\title{
Total Parenteral Nutrition-Associated Alterations in Hepatobiliary Function and Histology in Rats: Is Light Exposure a Clue? ${ }^{1}$
}

\author{
JATINDER BHATIA, MARY TREINEN MOSLEN, ABIDA K. HAQUE, \\ RENEE MCCLEERY, AND DAVID K. RASSIN \\ Departments of Pediatrics, Pharmacy, and Pathology, The University of Texas Medical Branch at Galveston, \\ Galveston, Texas 77550
}

\begin{abstract}
Light exposure of amino acids, especially in the presence of photosensitizers such as riboflavin, has been shown to result in photoproducts that are toxic both in vivo and in vitro. Provision of photooxidized single amino acids has been shown to result in hepatic dysfunction in both gerbils and rats. However, studies of the effects of light exposure of complete nutrient mixtures (glucoseamino acid-vitamins) on hepatobiliary responses are limited. These are important because, in clinical practice, total parenteral nutrition (TPN) solutions are continually exposed to light and because hepatic dysfunction is the most common metabolic aberration associated with TPN. Studies were conducted to compare the effects of TPN that had been exposed to light $(+\mathrm{L})$ or protected from light $(-\mathrm{L})$ on hepatobiliary function of rats. TPN solutions were either exposed to light or protected from light for $24 \mathrm{~h}$ and then infused into rats for $\mathbf{1 0} \mathrm{d}$. Data for enterally fed rats are also shown for comparison with parenterally fed animals. $+\mathrm{L}$ animals lost more weight and had lower bile flow, higher taurocholate output in bile, higher biliary osmolarity, and higher inorganic phosphate in bile. Hepatic histology demonstrated scattered foci of necrosis in eight of the eight $+L$ animals and in only one of eight $-L$ animals. These data demonstrate that protection of TPN solutions from light minimizes TPN-associated alterations in hepatobiliary function and histology. These histologic changes observed in the $+\mathrm{L}$ animals are in contrast to previous reports of TPN-induced histologic changes, suggesting a different mechanism. Our observations suggest that consideration be given to the implications of exposing TPN solutions to light. (Pediatr Res 33: 487-492, 1993)
\end{abstract}

\section{Abbreviations}

TPN, total parenteral nutrition

$+\mathrm{L}$, exposed to light (experimental condition)

$-\mathrm{L}$, protected from light (experimental condition)

GGT, $\gamma$-glutamyl transferase

PT, portal tract

$\mathrm{Pi}$, inorganic phosphate

Hepatic dysfunction is a complication of TPN and has been reported as early as $5 \mathrm{~d}$ after $\operatorname{TPN}(1,2)$. Onset of hepatobiliary

Received August 31, 1992; accepted December 29, 1992.

Correspondence and reprint requests: Jatinder Bhatia, M.B., B.S., BG 114

Department of Pediatrics, Medical College of Georgia, Augusta, GA 30912-3740.

Supported by Grant HD22828 from the National Institutes of Health.

${ }^{1}$ Presented in part at the Society for Pediatric Research Meetings, May 1990 Anaheim, CA. dysfunction is insidious, with a progressive slow rise in biochemical indices of impaired function (3-5) in otherwise asymptomatic subjects. The incidence of this complication increases with duration of TPN $(3,6,7)$. Many factors have been postulated to contribute to TPN-induced hepatic dysfunction, including photooxidized products of amino acids $(1,8-11)$, amino acid imbalance (12), and other toxic components in TPN (13). We have previously reported adverse effects on hepatobiliary function (biliary reduced glutathione, $\mathrm{Pi}$, amino acids) due to light exposure of parenteral nutrients (14). In a typical clinical setting, TPN mixtures may be continuously exposed to light and hypocaloric TPN is often provided for the first 7 to $10 \mathrm{~d}$ of initiation of TPN as the nutrient intakes are being advanced. The objective of this study was to determine whether the beneficial effects of protecting TPN mixtures from light during short-term TPN (14) would persist after a more prolonged course of TPN.

\section{MATERIALS AND METHODS}

Animal preparation. The study was approved by the Institutional Animal Care and Use Committee. Male Sprague-Dawley rats $(250$ to $300 \mathrm{~g}$ ) were obtained from Harlan Sprague-Dawley (Indianapolis, IN) and allowed a 5- to 7-d period of acclimization, during which they were allowed free access to chow (LabChow 5008, Purina, St. Louis, MO) and water. The animals were housed in a temperature-controlled room $\left(22^{\circ} \mathrm{C}\right)$ with a $14-\mathrm{h} / 10$ $\mathrm{h}$ light/dark cycle. After this period, the internal jugular vein was cannulated and exteriorized as previously described (15). The animals were placed in individual cages and attached to a swivel apparatus that allowed free movement within the cages, and infusions of the respective solutions (assigned at random) were begun. A blood sample was obtained from the cannula before the onset of TPN infusion. For comparative purposes, we included a group of rats that underwent the same surgical procedures and were also placed in metabolic cages and attached to the swivel apparatus; their cannulas were flushed with heparinized saline periodically to maintain patency. These rats, the CHOW group, were fed LabChow 5008 ad libitum.

$T P N$ preparation. The TPN solutions were prepared in the hospital pharmacy under a laminar flow hood using a high-flow mixer. The composition of the TPN solution is depicted in Table 1 . The volume of TPN needed for a $24-\mathrm{h}$ infusion was placed in plastic syringes, appropriate amounts of a multivitamin infusate were added, and syringes were placed under a standard bank of fluorescent lights for light exposure $(+\mathrm{L})$ or were covered with aluminum foil for protection from light $(-\mathrm{L})$. The light exposure was maintained at $6 \mu \mathrm{W} \cdot \mathrm{cm}^{-2} \cdot \mathrm{nm}$ in the $425-$ to $475-\mathrm{nm}$ wave band for a 24-h period. Solutions exposed to light were noted to be paler after the light exposure. However, no appreciable changes in amino acid concentrations were observed after light exposure. This may be due to the following reasons: 1) changes 
Table 1. Composition of TPN solution

\begin{tabular}{lc}
\hline \multicolumn{1}{c}{ Nutrient } & Amount $(/ \mathrm{L})$ \\
\hline Amino acids* & $44.5 \mathrm{~g}$ \\
Dextrose $(50 \%)$ & $139.0 \mathrm{~g}$ \\
$\mathrm{NaCl}$ & $33.0 \mathrm{mEq}$ \\
$\mathrm{KCl}$ & $33.0 \mathrm{mEq}$ \\
$\mathrm{MVI} \dagger$ & $7.0 \mathrm{~mL}$ \\
\hline
\end{tabular}

* Aminosyn $10 \%$, Abbott Laboratories, Irving, TX.

$\dagger$ Each $5 \mathrm{~mL}$ contains: dexpanthenol, $25 \mathrm{mg}$; niacinamide, $100 \mathrm{mg}$; vitamin $A, 10000 \mathrm{IU}$; vitamin $B_{1}, 50 \mathrm{mg}$; vitamin $B_{2}, 10 \mathrm{mg}$; vitamin $\mathrm{B}_{6}, 15 \mathrm{mg}$; vitamin $\mathrm{C}, 500 \mathrm{mg}$; vitamin $\mathrm{D}, 1000 \mathrm{IU}$; vitamin E, $5 \mathrm{IU}$. MVI (multivitamin infusate) was added to the infusate just before light exposure (see text).

Table 2. Effects on body and organ weights*

\begin{tabular}{lcccc}
\hline Group & Beginning $(\mathrm{g})$ & End $(\mathrm{g})$ & $\begin{array}{c}\text { Liver wt } \\
(\% \text { body wt) }\end{array}$ & $\begin{array}{c}\text { Brain wt } \\
(\% \text { body wt })\end{array}$ \\
\hline$+\mathrm{L}(n=8)$ & $254 \pm 12$ & $220 \pm 22 \dagger$ & $3.97 \pm 1.75$ & $0.62 \pm 0.24$ \\
$-\mathrm{L}(n=8)$ & $267 \pm 12$ & $239 \pm 12 \ddagger$ & $3.49 \pm 1.28$ & $0.63 \pm 0.07$ \\
CHOW $(n=6)$ & $270 \pm 18$ & $275 \pm 14$ & $3.42 \pm 0.27$ & $0.52 \pm 0.09$
\end{tabular}

$*$ Values are expressed as mean $\pm \mathrm{SD}$.

$\dagger p=0.034 v s-\mathrm{L}$.

$\ddagger p=0.001$ vs CHOW.

in concentrations are small, as we noted earlier (16), and 2) differences in concentrations could not be discerned by ninhydrin-based amino acid analysis. Fresh solutions were prepared daily and subjected to light exposure as described. The solutions were protected from light during infusion. It should be pointed out that although the light exposure is similar to that experienced in neonatal nurseries, the infusion of solutions for $24 \mathrm{~h}$ after light exposure is not carried out. Because we were interested in developing a model in which an adverse effect of light exposure could be assessed and we could not subject the rats to phototherapy, we developed a protocol for light exposure that could be controlled.

TPN solutions were infused at a rate of $200 \mathrm{~mL} \cdot \mathrm{kg}^{-1} \cdot \mathrm{d}^{-1}$, which provided the rat with approximately $130 \mathrm{kcal} \cdot \mathrm{kg}^{-1} \cdot \mathrm{d}^{-1}$.

At the end of the 10-d period, animals were weighed and anesthetized with ketamine, bile ducts were cannulated, and bile was collected for a 4-h period in hourly aliquots into tared tubes. Infusions of the respective solutions were continued. Bile flow was measured gravimetrically. The animals were maintained anesthetized during this period $[0.1 \mathrm{~mL}$ of ketamine $(100 \mathrm{mg}$. $\mathrm{mL}^{-1}$ ) given intramuscularly, hourly as required]. The animals were then killed by exsanguination, and livers and brains were removed, blotted dry, and weighed. Serum and bile were stored at $-70^{\circ} \mathrm{C}$ until analysis.

The following analyses were performed: 1) Serum was analyzed for GGT activity based on the transfer of the $\tau$-glutamyl group from L-glutamyl-p-nitroanilide to glycylglycine catalyzed by GGT, and the absorbance after $p$-nitroaniline was diazotized and $\mathrm{N}$-(1-naphthyl)-ethylenediamine was added (Sigma Diagnostics, St. Louis, MO) was subsequently measured. Total bile acids were analyzed by an enzymatic method in which the $3 \alpha$ - hydroxysteroid dehydrogenase transferred the $3 \alpha$-hydroxyl groups to corresponding keto forms and subsequently generated NADH from NAD (Sterognost 3 alpha Flu, Nyegaard and Co., Oslo, Norway). 2) Bile was analyzed for GGT, Pi (17), total protein, osmolarity by freeze-point osmometry (Advanced Instruments Osmometer, model 3W, Needham Heights, MA); and total bile acids (Sterognost 3 alpha Pho). Individual conjugated bile acids were determined on HPLC by the method of Bloch and Watkins (18), using a methanol-acetic acid mixture and a refractive index detector. Identification of the following bile acids was attempted: taurocholate, taurochenodeoxycholate, taurodeoxycholate, glycocholate, glycochenodeoxycholate, cholic acid, lithocholic acid, murocholic acids, sodium, and potassium (flame photometry). 3) Liver was analyzed for total protein.

Histopathologic examination. Thin slices of liver were obtained from each rat, one each from the center of the left lobe, the right lateral lobe, and the triangular lobe. The histologic sections together measured approximately $2.0 \times 1.5 \mathrm{~cm}$. The liver slices were fixed in $10 \%$ buffered formaldehyde for at least $1 \mathrm{wk}$, embedded in paraffin, and sectioned at $4 \mu \mathrm{m}$. The sections were processed in a standard manner, stained with hematoxylin and eosin, cleared, and coverslipped. The slides were examined by one investigator (A.H.) using $40 \times$ to $200 \times$ magnification, who was blinded to the treatment group.

Each section was carefully examined for changes in PT, central veins, and hepatocytes. The total number of PT, as well as the PT showing inflammation, was enumerated. PT inflammation was conservatively considered to be present if more than 10 cells were counted. An average cell count per PT was obtained by counting and averaging the inflammatory cells within five PT. The nature of cells in these PT i.e. whether they were mononuclear cells or neutrophils, was also determined. The lobules were examined for presence of fatty change and hepatocyte necrosis. The hepatocyte necrosis was graded 0 to $4+$ based on visual assessment of the percentage of lobular area involved by necrosis as follows: $0=$ no necrosis; $1+=1$ to $2 \%$ of lobule involved; $2+=3$ to $5 \% ; 3+=6$ to $9 \%$; and $4+=>10 \%$ of the lobular area involved. Rare foci of two- to three-cell necrosis were noted as such and not graded.

Statistical analysis. All data are expressed as mean \pm SD. Data were analyzed by analysis of variance using treatments $(+\mathrm{L}$ or $-\mathrm{L}$ ) and time (pre- and postinfusion, or hours of bile collection) as factors. Significance was set at $p<0.05$; if achieved, post hoc analyses used the $t$ test.

\section{RESULTS}

$+\mathrm{L}$ animals $(n=8)$ received $193 \pm 16 \mathrm{~mL} \cdot \mathrm{kg}^{-1} \cdot \mathrm{d}^{-1}, 8.6 \pm 0.7$ $\mathrm{g}$ amino acids, and $126 \pm 10 \mathrm{kcal} \cdot \mathrm{kg}^{-1} \cdot \mathrm{d}^{-1}($ mean $\pm \mathrm{SD})$, whereas the $-\mathrm{L}$ animals $(n=8)$ received $198 \pm 5 \mathrm{~mL} \cdot \mathrm{kg}^{-1} \cdot \mathrm{d}^{-1}, 8.8 \pm$ $0.2 \mathrm{~g}$ amino acids, and $129 \pm 0.1 \mathrm{kcal} \cdot \mathrm{kg}^{-1} \cdot \mathrm{d}^{-1}$. No attempt was made to quantify the amount of chow consumed by the animals in the CHOW group.

Beginning body weights of the $+\mathrm{L},-\mathrm{L}$, and CHOW groups were similar $(254 \pm 12,267 \pm 12$, and $270 \pm 18 \mathrm{~g}$, respectively, $p=0.08$; Table 2). However, by the end of the $10-\mathrm{d}$ period, animals in the $+\mathrm{L}$ group had significantly lower body weights

Table 3. Effects on bile flow and biliary concentrations of total bile acid, GGT, Pi, and osmolarity*

\begin{tabular}{lccccc}
\hline Group & $\begin{array}{c}\text { Bile flow } \\
\left(\mu \mathrm{L} \cdot \mathrm{h}^{-1}\right)\end{array}$ & $\begin{array}{c}\text { Bile acid } \\
\left(\mu \mathrm{mol} \cdot \mathrm{h}^{-1}\right)\end{array}$ & $\begin{array}{c}\text { GGT } \\
\left(\mathrm{U} \cdot \mathrm{mL}^{-1}\right)\end{array}$ & $\begin{array}{c}\mathrm{Pi} \\
(\mu \mathrm{M})\end{array}$ & $\begin{array}{c}\text { Osmolarity } \\
\left(\mathrm{mosmol}^{-1}\right)\end{array}$ \\
\hline +L & $564 \pm 151 \dagger$ & $15 \pm 7 \dagger$ & $3.8 \pm 1.9 \dagger$ & $39.8 \pm 10.6 \dagger \ddagger$ & $356 \pm 72 \dagger$ \\
-L & $716 \pm 351 \dagger \S$ & $13 \pm 6 \dagger$ & $3.1 \pm 3.3 \dagger$ & $9.0 \pm 6.0$ & $288 \pm 12 \ddagger$ \\
CHOW & $1115 \pm 47$ & $43 \pm 9$ & $10.2 \pm 3.9$ & $11.1 \pm 3.0$ & $293 \pm 31$ \\
\hline
\end{tabular}

* Values are expressed as mean $\pm \mathrm{SD}$.

$+p<0.001$ vs CHOW.

$¥ p<0.001 v s+\mathrm{L}$.

$\S p<0.05 v s+\mathrm{L}$. 


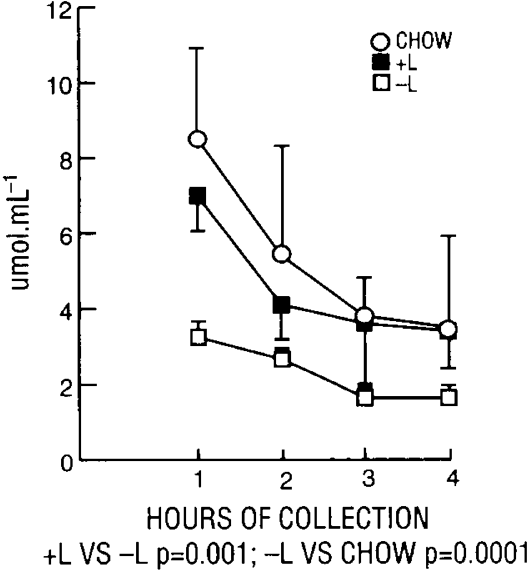

Fig. 1. Biliary taurocholate concentration $\left(\mu \mathrm{mol} \cdot \mathrm{mL}^{-1}\right)$.

than those in the $-\mathrm{L}$ and CHOW groups (Table 2). $+\mathrm{L}$ animals lost an average of $3.3 \mathrm{~g} / \mathrm{d}$, whereas the $-\mathrm{L}$ animals lost $2.6 \mathrm{~g} / \mathrm{d}$. The weight loss demonstrated in these animals is probably not significant clinically and is similar to that reported by other investigators during hypocaloric TPN (19). There were no significant differences in liver or brain weights in these animals (Table 2).

Table 3 summarizes the major effects on biliary parameters. $-\mathrm{L}$ animals had lower biliary $\mathrm{Pi}$ and osmolarity than the $+\mathrm{L}$ animals. Biliary $\mathrm{Pi}$ and osmolarity of the $-\mathrm{L}$ animals were close to the values of the $\mathrm{CHOW}$ animals, whereas the $+\mathrm{L}$ animals had higher biliary Pi and osmolarity than the CHOW group. Bile flow (Table 3) was significantly higher in the -L animals compared with the $+\mathrm{L}$ animals. Biliary bile output was similar in the two TPN groups, but significantly $(p=0.001)$ lower than in the CHOW group. Total conjugated bile acid concentration was significantly $(p=0.0213)$ greater in the $+\mathrm{L}$ versus $-\mathrm{L}$ animals, and the $-\mathrm{L}$ concentration was significantly lower than the CHOW concentration ( $p=0.0013$; data not shown). There were significant differences for the individual bile acids between the two groups: taurocholate was significantly $(p<0.01)$ greater in the $+\mathrm{L}$ versus $-\mathrm{L}$ animals, and in both parenteral groups it was significantly lower than in the CHOW group (Fig. 1). The concentration of this bile acid decreased significantly with time of collection. Biliary output of taurodeoxycholate was similar to that of taurocholate, with $\mathrm{CHOW}$ animals having a greater output than $+\mathrm{L}$ or $-\mathrm{L}$ animals (data not shown). Hourly output for taurochenodeoxycholate was significantly greater in CHOW versus $+\mathrm{L}$ or $-\mathrm{L}$ animals and decreased with time of collection; outputs of glycocholic and cholic acids did not differ between the groups, whereas glycochenodeoxycholate was significantly lower in the $+\mathrm{L}$ versus $-\mathrm{L}$ animals and greater in $-\mathrm{L}$ versus CHOW animals. Neither murocholic nor lithocholic acids were detected in these biles.

There were no significant differences between the two groups in biliary sodium, potassium, or liver protein (data not shown).

Histopathologic findings. In the $-\mathrm{L}$ group, only one of eight rats had appreciable foci of hepatic necrosis (grade 1+), which were located in the periportal and midzonal regions. In contrast, foci of hepatic necrosis were seen in all eight rats in the $+\mathrm{L}$ group, seven with grade $1+$ and one with grade $2+$. Figure 2 shows a typical focus of midzonal necrosis in the $+\mathrm{L}$ group. Foci in the $+\mathrm{L}$ group were usually observed in both the midzonal and periportal regions; foci were found only in the periportal region in one rat and in all regions in only one rat. Figure 3 shows the more atypical large foci with readily identifiable inflammatory cell infiltrate that was observed in the majority of livers examined.

PT inflammation was more prominent in the $+\mathrm{L}$ group, with a very significant increase in the number of inflammatory cells per PT $(85.9 \pm 22.2$ versus $33.9 \pm 8.2, p=0.0001)$. PT from all eight animals in the $+\mathrm{L}$ group had both macrophages and neutrophils, whereas neutrophils were not identified in PT from seven of eight animals in the -L group. No fatty change, cholestasis, or fibrosis was seen in either group.

\section{DISCUSSION}

Our results demonstrate significant alterations in both biochemical indicators of hepatic function and hepatic histology in

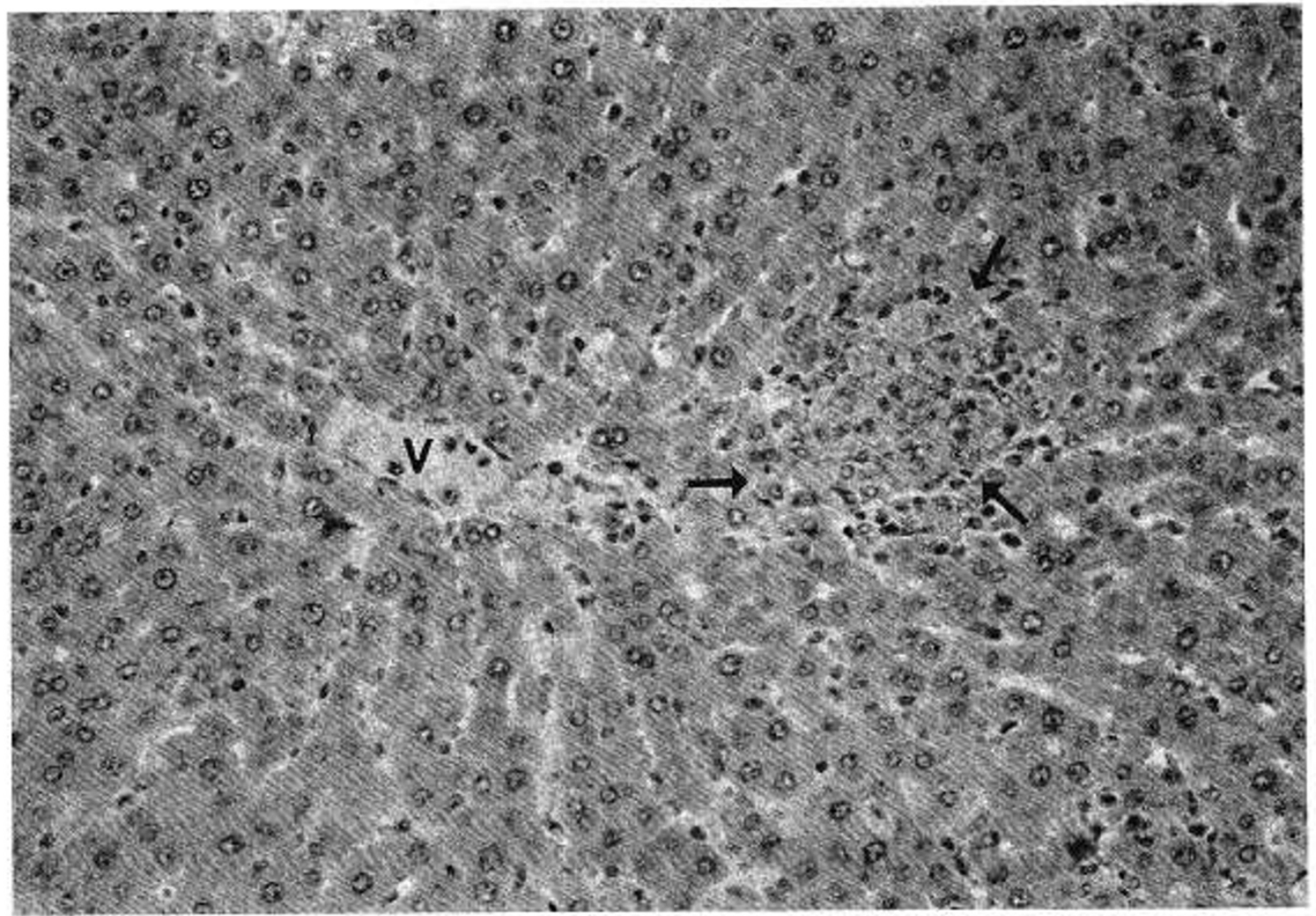

Fig. 2. A typical focus of midzonal necrosis in this $+\mathrm{L}$ group. Central vein $(V)$ is seen in the center of the field (arrows denote the zone) $(\times 200)$. 


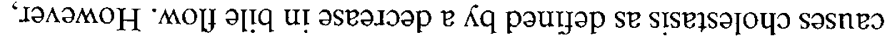

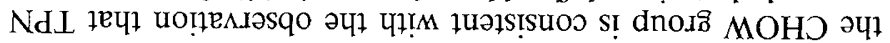

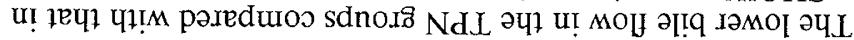

aInsodxə

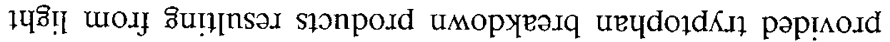

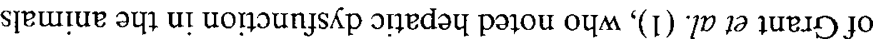

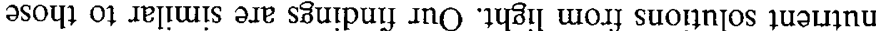

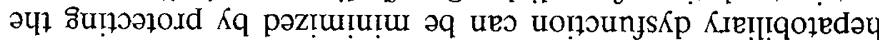

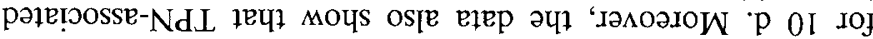

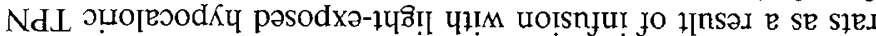

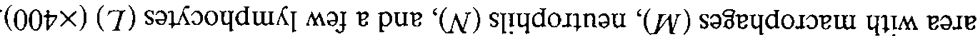

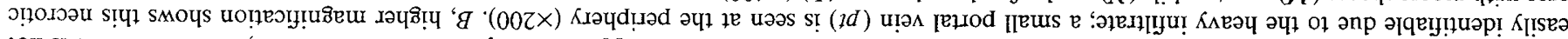

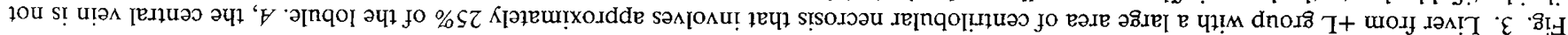

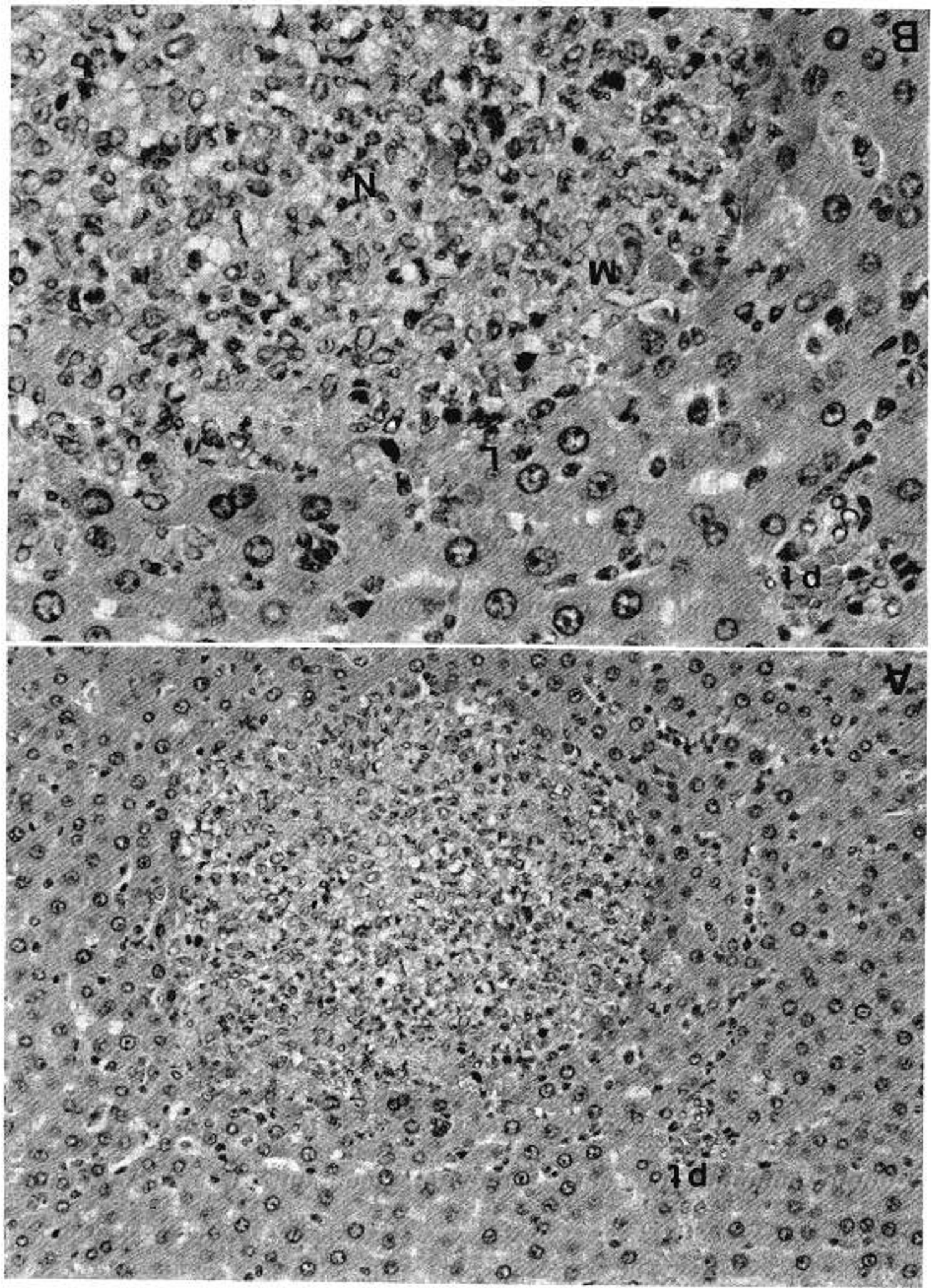


it is interesting to note that bile flow is lower in the $+\mathrm{L}$ animals than in the $-\mathrm{L}$ animals despite similar total bile acid output. These data are somewhat similar to those of Lirussi et al. (20). These investigators reported a decrease in bile acid secretion in both TPN-fed and enterally fed control animals in the first few hours after bile duct cannulation. However, bile acid secretion was significantly greater in TPN-fed versus control animals, whereas bile flow was similar in the two groups, suggesting that bile acid-independent flow was affected by TPN.

Biliary $\mathrm{Pi}$, a putative marker of leaky tight junctions, was higher in the $+\mathrm{L}$ animals compared with $-\mathrm{L}$ animals, suggesting greater paracellular permeability due to infusion of light-exposed TPN. The exact components of TPN or the mechanism(s) that cause the increased leakage are not known but have been observed in hepatic dysfunction caused by other agents (21).

In contrast to the majority of previous reports of TPN-induced histologic changes of fatty infiltration, cholestasis, inflammatory PT lesions, portal fibrosis, canalicular bile stasis, Kupffer cells, and macrophages containing lipofuscin pigment, biliary sludge, and bile duct proliferation $(1,7,22-29)$, the $+\mathrm{L}$ animals in our study demonstrated appreciable hepatocyte necrosis in addition to inflammatory cells-macrophages and neutrophils. We did not expect to see the other findings, such as fatty infiltration, usually seen with TPN because of the hypocaloric nature of the TPN regimen. We chose the lower amount of energy while maintaining maximal amino acid intake for the following reasons: 1) In clinical practice, actual energy intakes achieved in the first 7 to $10 \mathrm{~d}$ after beginning TPN are modest, whereas amino acid intake reaches its maximum; the amino acid intake chosen by us represents $25 \%$ of the total dietary energy intake of chow-fed rats and represents what has been fed to rats in various studies. The requirement of the rat for protein is considerably greater than that of man 2) Rats provided higher energy intakes demonstrate fatty livers $(7,30-31)$. Craig et al. (32) reported hepatocyte necrosis in one patient after $16 \mathrm{wk}$ of TPN after small bowel resection. These investigators also reported the progression of fibrosis and inflammatory changes with continuing TPN. The hepatocyte necrosis suggests that light exposure of the TPN solutions resulted in compounds that may be considered toxic to the animals. These findings cannot be attributed to either enteral starvation or hypocaloric regimens because treatment of both groups of animals was similar, as was the weight loss.

The most likely group of nutrients in TPN responsible for the alterations in hepatobiliary function are amino acids, because several amino acids (tryptophan, methionine, tyrosine, histidine and cysteine) are readily photooxidized in the presence of a variety of photosensitizers, including vitamins such as riboflavin (14, 33-47). In vitro studies have demonstrated that, in the presence of light, lysine and tryptophan are inhibitory to growth of lung fibroblasts in culture (47). In addition, when single amino acids were irradiated in the presence of vitamins, cysteine and tryptophan were inhibitory to cell growth, and methionine became toxic; the toxicity was only noted in the presence of riboflavin, biotin, or folic acid. Other in vitro studies have demonstrated lethal and inhibitory effects of irradiated amino acids $(48,49)$. Irradiation of tryptophan and riboflavin with visible fluorescent or near-UV light resulted in products that caused single-strand breaks in DNA of mammalian cells (50). In contrast to these studies demonstrating toxicity of amino acids exposed to light, human plasma irradiated with light failed to support growth of human cells in culture, but growth was restored by the addition of the amino acids most depleted by light exposure-tryptophan and cysteine (51). It should be pointed out that, in general, the depletion of amino acids by photooxidation is a small percentage of the total, increasing the likelihood of toxic products as the mechanism of the observed effects.

In summary, our data demonstrate alterations in hepatobiliary function and histology due to infusion of light-exposed TPN. The histopathologic findings reported herein are different from the usual findings of TPN-associated hepatic dysfunction, suggesting a different mechanism for the liver injury noted. Clinical implications of light-exposed TPN infusions, especially in groups of subjects susceptible to hepatic dysfunction from TPN, need to be considered.

Acknowledgments. The authors thank Suzanne McMillan Horlick for her technical assistance and Peggy A. King for her secretarial assistance.

\section{REFERENCES}

1. Grant JP, Cox CE, Kleinman LM, Maher NM, Pitman MA, Tangrea JA Brown JH, Gross E, Beazley RM, Jones RS 1977 Serum hepatic enzyme and bilirubin elevations during parenteral nutrition. Surg Gynecol Obstet 145:573-580

2. Wagner WH, Lowry AC, Silberman H 1983 Similar liver function abnormalities occur in patients receiving glucose-based and lipid-based parenteral nutrition. Am J Gastroenterol 78:199-202

3. Beale EF, Nelson RM, Bucciarelli RL, Donnely WH, Eitzman DV 1979 Intrahepatic cholestasis associated with parenteral nutrition in premature infants. Pediatrics 64:342-347

4. Periera GR, Sherman MS, DiGiacoma J, Ziegler M, Roth J, Jacobowski D 1981 Hyperalimentation-induced cholestasis: increased incidence and severity in premature infants. Am J Dis Child 135:842-845

5. Farrell MK, Balisteri WF, Suchy FJ 1982 Serum sulfated lithocholate as an indicator of cholestasis during parenteral nutrition in infants and children. $J$ Parent Enteral Nutr 6:32-33

6. Sondheimer JH, Bryon H, Andrews W, Forstner GC 1978 Cholestatic tendencies in premature infants on and off parenteral nutrition. Pediatrics 63:984-989

7. Messing B, De Oliveira FJ, Galian A, Bernier JJ 1982 Cholestasis during total parenteral nutrition: demonstration of facilitating factors and association with gallbladder lithiasis. Gastroenterol Clin Biol 6:740-747

8. Merritt RJ, Sinatra FR, Henton DH, Neustein H 1984 Cholestatic effect of intraperitoneal administration of tryptophan to suckling rat pups. Pediatr Res 18:904-908

9. Bhatia J, Rassin DK 1985 Photosensitized oxidation of tryptophan and hepatic dysfunction in neonatal gerbils. JPEN 9:4-9

10. Donoso M de LN, Valenzuela A, Silva E 1988 Tryptophan-riboflavin photoinduced adduct and hepatic dysfunction in rats. Nutr Rep Int 37:599-606

11. Silva E, Salim-Hanna M, Becker MI, Ioannes A 1988 Toxic effects of a photoinduced tryptophan-riboflavin adduct on F9 tetracarcinoma cells and preimplantation mouse embryos. Int J Vit Res 58:394-401

12. Sheldon GF, Peterson SR, Sanders R 1978 Hepatic dysfunction during hyperalimentation. Arch Surg 113:504-508

13. Balistreri WF, Bove KE 1990 Hepatobiliary consequences of parenteral alimentation. In: Popper H, Schaffner F (eds) Progress in Liver Disease, IX. WB Saunders, Philadelphia, pp 567-601

14. Bhatia J, Moslen MT, Kaphalia L, Rassin DK 1992 Glutathione and tissue amino acid responses to light-exposed parenteral nutrients. Toxicol Lett 63:79-89

15. Rivera A, Bhatia J, Rassin DK, Gourley WK, Catarau E 1989 In vivo biliary function in the adult rat: the effect of parenteral glucose and amino acids. J Parenter Enteral Nutr 13:240-245

16. Bhatia J, Stegink LD, Ziegler EE 1983 Riboflavin enhances photooxidation of amino acids under simulated clinical conditions. J Parenter Enteral Nutr 7:277-279

17. Moslen MT, Kanz MF, Ferguson AE 1988 A stable colorimetric assay to measure toxin elevation in inorganic phosphate in bile. Anal Biochem 168:405-410

18. Bloch CA, Watkins JB 1978 Determination of conjugated bile acids in human bile and duodenal fluid by reverse-phase high-performance liquid chromatography. J Lipid Res 19:510-513

19. Scott RL, Abina JE, Caldwell MD 1982 Effects of hypocaloric dextrose and amino acids on body composition and nitrogen balance in rats. $J$ Parenter Enteral Nutr 6:489-495

20. Lirussi F, Vaja S, Murphy GM, Dowling RH 1989 Cholestasis of total parenteral nutrition: bile acid and bile lipid metabolism in parenterally nourished rats. Gastroenterology 96:493-502

21. Ballatori N, Troung AT 1990 Cholestasis, altered junctional permeability and inverse changes in sinusoidal and biliary glutathione release by vasopressin and epinephrine. Mol Pharmacol 38:64-71

22. Lindor KD, Fleming CR, Abrams A, Kirschkorn MA 1979 Liver function values in adults receiving total parenteral nutrition. JAMA 241:2398-2400

23. Lowry SF, Brennan MF 1979 Abnormal liver function during parenteral nutrition. Relation to infusion excess. J Surg Res 26:300-307

24. Cohen C, Olsen MM 1981 Pediatric total parenteral nutrition: liver histopathology. Arch Pathol Lab Med 105:152-156

25. Dahms BB, Halpin TC 1981 Serial liver biopsies in parenteral nutritionassociated cholestasis of early infancy. Gastroenterology 81:136-144

26. Benjamin DR 1981 Hepatobiliary dysfunction in infants and children associated with long-term parenteral nutrition. A clinic-pathologic study. Am J Clin Pathol 76:276-283 
27. Hodes JE, Grosfeld JL, Weber TR, Schreiner RL, Fitzgerald JF, Mirkin D 1982 Hepatic failure in infants on total parenteral nutrition (TPN): clinical and histopathologic observations. J Pediatr Surg 17:463-468

28. Berger HM, Den Ouden AL, Calame JJ 1985 Pathogenesis of liver damage during parenteral nutrition: is lipofusion a clue? Arch Dis Child 60:774-776

29. Chang S, Silvis SE 1974 Fatty liver produced by hyperalimentation of rats. Am J Gastroenterol 63:410-418

30. Martins FM, Wennberg A, Kihlberg R, Meurling S, Lindmark L 1985 Total parenteral nutrition with different ratios of fat/carbohydrate at two energy levels: an animal study. J Parenter Enteral Nutr 9:47-52

31. Machytka B, Hoos I, Forster H 1977 Fatty liver in rats following parenteral hyperalimentation with glucose and glucose assay to measure toxin elevation in inorganic phosphate in bile. Anal Biochem 168:405-410

32. Craig RM, Neumann T, Jeejeebhoy KN, Yokoo H 1980 Severe hepatocellular reaction resembling alcoholic hepatitis with cirrhosis after massive bowel resection and prolonged total parenteral nutrition. Gastroenterology 79:131137

33. Dose K, Rajewsky B 1962 Photochemistry of sulfur containing amino acids and peptides. Photochem Photobiol 2:181-189

34. Weil L, Gordon WG, Buchert AR 1951 Photooxidation of amino acids in the presence of methylene blue. Arch Biochem Biophys 33:90-109

35. Forbes WF, Rivett DE, Savige WE 1962 Photolysis and photooxidation of amino acids and peptides. III. Effect of ionizing radiation on cystine and related acids. Photochem Photobiol 1:97-103

36. Forbes WF, Savige WE 1962 Photolysis and photooxidation of amino acids and peptides. I. Irradiation of aqueous solutions of cystine with sunlight and other ultraviolet light sources. Photochem Photobiol 1:1-13

37. Bowen JR, Yang SF 1975 Photosensitized deamination of sulfur-amino acids by flavin mononucleotide. Photochem Photobiol 21:201-203

38. Gurnani S, Arifuddin M 1966 Effect of visible light on amino acids. II. Histidine. Photochem Photobiol 5:341-345

39. Lukton A, Weisbrod R, Schlesinger J 1965 The effect of imidazole ring substitution on the rate of its photooxidation. Photochem Photobiol 4:277279

40. Johnson PG, Bell AP, McCormick DB 1975 Flavin-sensitized photooxidation of histidine. Photochem Photobiol 21:205-208

41. Enns K, Burgess WH 1965 The photochemical oxidation of ethylene diaminetetraacetic acid and methionine by riboflavin. J Am Chem Soc 87:57665770

42. Jori G, Galiazzo G, Marzotto A, Scoffone E 1968 Dye-sensitized selective photooxidation of methionine. Biochim Biophys Acta 154:1-9

43. Benassi CA, Scoffone E, Galiazzo G, Jori G 1967 Proflavine-sensitized photooxidation of tryptophan and related peptides. Photochem Photobiol 6:857 866

44. Gurnani S, Arifuddin M, Augusti KT 1966 Effect of visible light on amino acids. I. Tryptophan. Photochem Photobiol 5:495-505

45. Bhatia J, Mims LC, Roesel RA 1980 The effect of phototherapy on amino acid solutions containing multivitamins. J Pediatr 96:284-286

46. Bhatia J, Rassin DK, McAdoo DJ 1991 Photosensitized oxidation of tryptophan: effect on liver and brain tryptophan. J Parenter Enteral Nutr 15:637641

47. Litwin J 1972 The effect of light on the aging of human diploid fibroblasts. Exp Gerontol 7:381-386

48. Nixon TB, Wang RJ 1977 Formation of photoproducts lethal for human cells in culture by daylight fluorescent light and bilirubin light. Photochem Photobiol 26:589-591

49. Stoein JD, Wang RJ 1974 Effect of near-ultraviolet and visible light on mammalian cells in culture. II. Formation of toxic photoproducts in tissue culture medium by black light. Proc Natl Acad Sci USA 71:3961-3965

50. Hoffman ME, Menenghini R 1979 DNA strand breaks in mammalian cells exposed to light in the presence of riboflavin and tryptophan. Photochem Photobiol 29:299-303

51. Englehardt DL, Santella RM, Rosenkranz HS, Speck WT 1977 The effect of illuminated human plasma on cell growth. Photochem Photobiol 26:53-55 